\title{
The new genus of stick insect Lobofemora from Vietnam, with the description of three new species (Phasmida: Phasmatidae: Clitumnini)
}

\author{
Joachim BRESSEEL ${ }^{1}$ \& Jérôme CONSTANT ${ }^{2}$ \\ ${ }^{1,2}$ Royal Belgian Institute of Natural Sciences, O.D. Phylogeny and Taxonomy, Entomology, \\ Vautier street 29, B-1000 Brussels, Belgium. \\ 11Email: joachimbresseel@gmail.com (corresponding author) \\ ${ }^{2}$ Email: jerome.constant@naturalsciences.be \\ ${ }^{1}$ urn:1sid:zoobank.org:author:3C4EF358-9716-46F0-8575-26BE1EDE4349 \\ ${ }^{2}$ urn:1sid:zoobank.org:author:6E6072A1-9415-4C8D-8E60-2504444DB290
}

\begin{abstract}
The new genus Lobofemora gen. nov. is described from Vietnam to accommodate three new species: L. bachmaensis sp. nov. (Bach Ma National Park, central Vietnam), L. bidoupensis sp. nov. (Bidoup-Nui Ba National Park, central Vietnam) and L. scheirei sp. nov., the type species (Cat Tien National Park and Dong Nai Biosphere Reserve, south Vietnam). It is provisionally placed in the tribe Clitumnini Brunner von Wattenwyl, 1893. The genus is the only known Clitumnini which shows tegmina and sometimes alae in the males. Females show conspicuous foliaceous lobes on the median femora. Males and females of all species and the eggs of L. scheirei sp. nov. and L. bidoupensis sp. nov. are described and illustrated. An identification key to the species and a distribution map are provided. The definition of the tribe Clitumnini sensu Hennemann \& Conle (2008) is slightly adapted to include the new genus and the tribal placement is discussed. The male of $L$. scheirei sp. nov. is able to stridulate by rubbing the outer margins of the tegmina against the subcostal and radial veins of the alae.
\end{abstract}

Keywords. Phasmatodea, stridulation, Global Taxonomic Initiative, South-East Asia, walking stick.

Bresseel J. \& Constant J. 2015. The new genus of stick insect Lobofemora from Vietnam, with the description of three new species (Phasmida: Phasmatidae: Clitumnini). European Journal of Taxonomy 115: 1-25. http://dx.doi. org/10.5852/ejt.2015.115

\section{Introduction}

The tribe Clitumnini Brunner von Wattenwyl, 1893 was recently re-diagnosed and revised on the generic level by Hennemann \& Conle (2008). The tribe comprises fourteen genera, some of which are very species rich, e.g., Ramulus Saussure, 1862 (171 species, see Brock 2015) and Entoria Stål, 1875 (31 species, see Brock 2015). Recent expeditions to Vietnam in the frame of a Global Taxonomic Initiative project by the authors and Vietnamese colleagues have revealed three congeneric new species that could not be attributed to any known genus. Following the key of Hennemann \& Conle (2008), the new genus belongs in the tribe Clitumnini showing the following typical features: small to medium sized species with body lengths ranging from 71.2 to $95.5 \mathrm{~mm}$ in females and 52.5 to $74.0 \mathrm{~mm}$ in males; elongate legs; sexual dimorphism distinct; antennae shortened with the scapus enlarged, laterally dilated 
and consisting of less than 28 segments; both sexes with short, roughly cylindrical cerci; males with the anal segment consisting of two movable semitergites which are minutely dentated interiorly and lack a developed sclerotised external vomer. Furthermore, the very elongate eggs and hairy appendages on the outer border of the capitulum is a character shared with three other genera of Clitumnini.

The new genus, however, violates several characters of Clitumnini; hence, it is remarkable and interesting in several aspects. The mesothorax is less than $2.5 \mathrm{x}$ the combined length of head and prothorax in females. The median segment is about as long as the metanotum. Tegmina and often alae present in males, males have teeth on the mesofemora and have a granulose thorax. Females with back of the head raised and/or conical.

The new genus is described below as Lobofemora gen. nov. and is currently known from different localities in Central and South Vietnam. Lobofemora scheirei sp. nov. was found in the lowlands of Dong Nai Biosphere Reserve and Cat Tien National Park, both located in Southern Vietnam. Lobofemora bidoupensis sp. nov. is described from the highlands of Bidoup-Nui Ba National Park and Lobofemora bachmaensis sp. nov. is recorded from Bach Ma National Park in the Annamite Mountains, Central Vietnam.

\section{Material and methods}

Due to their nocturnal behaviour, most Phasmida including the genus Lobofemora gen. nov. were collected at night. A light-weight and water-proof head torch, Petzl MYO RXP, was used during searching the vegetation. The females were kept alive in a plastic box for producing eggs. Hatchlings of the different species were reared to adulthood by the first author and Dr Bruno Kneubühler (Switzerland). The wild caught specimens were euthanized with ethyl acetate fumes. The specimens were then stored in airtight plastic "zip"-bags in wood chips (used in rodent cages) and sprinkled with ethyl acetate (EtOAc) to prevent rotting, mould and keeping the specimens flexible. The bags are then frozen on arrival and the specimens are mounted later on.

The egg morphology follows the terminology of Clark Sellick $(1997,1998)$. The description of the colouration is based on live specimens.

\section{Acronyms used for the collections}

BMNH $=$ Natural History Museum, London, United Kingdom

FHC = Frank Hennemann Collection, Hohenecken, Germany

MNHU $=$ Museum für Naturkunde der Humboldt-Universität, Berlin, Germany

RBINS = Royal Belgian Institute of Natural Sciences, Brussels, Belgium

RMNH $=$ Nationaal Natuurhistorisch Museum (Naturalis), Leiden, The Netherlands

VNMN = Vietnam National Museum of Nature, Vietnamese Academy of Sciences, Hanoi, Vietnam

ZMUH = Zoologisches Museum, Universität Hamburg, Germany

ZSMC = Zoologische Staatssammlung München, Germany

\section{Results}

Family Phasmatidae Gray, 1835 sensu lato

Subfamily Clitumninae Brunner von Wattenwyl, 1893

Tribe Clitumnini Brunner von Wattenwyl, 1893

We follow the definition of the tribe proposed by Hennemann \& Conle (2008: 67), except for the following characters: 
1. The length of the median segment: Clitumnini have the median segment strongly shortened and at most $1 / 4$ the length of the metanotum; Lobofemora gen. nov. has the median segment about as long as the metanotum.

2. Relative length of mesothorax: Clitumnini have the mesothorax at least $2.5 \mathrm{x}$ the combined length of head and prothorax; Lobofemora gen. nov. has the mesothorax shorter than twice the combined length of head and prothorax.

Genus Lobofemora gen. nov.

urn:1sid:zoobank.org:act:5EBCBEF1-D0EA-4433-9B85-287709869730

\section{Type species}

Lobofemora scheirei sp. nov. by present designation.

\section{Etymology}

The name of the new genus is formed by the juxtaposition of lobus (Latin), meaning lobe and "femora". The name refers to the foliaceous lobes on the median legs of the females.

\section{Diagnosis}

Differing from all other know genera of Clitumnini by the following combination of characters:

1. Females with back of head more or less strongly raised, granulose and conical.

2. Males with at least some scale-like tegmina present, sometimes with developed alae.

3. Median segment about as long as or longer than metanotum.

4. Females with conspicuous enlarged lobes on mesofemora and males occasionally with dorsal teeth on the mesofemora.

5. Mesothorax less than $2.5 \mathrm{x}$ the length of head and pronotum combined.

6. Semi-tergites of males very short and broad and thorax densely granulose.

\section{Description}

\section{Male}

HEAD. Longer than wide, slightly tapering posteriorly and granulose. Vertex elongated. Dorsal portion of head flattened, with two definite spines positioned at posterior margin of eyes and projecting dorsally. Eyes circular and strongly projecting hemispherically. Scapus flattened dorso-ventrally and rounded laterally. Pedicellus cylindrical.

Thorax. Pronotum shorter than head and slightly widening posteriorly. Anterior margin incurved and raised, followed by faint, median longitudinal impression, not reaching posterior margin. Central transverse impression not reaching lateral edges of pronotum. Mesonotum granulose, widening posteriorly. Fine median longitudinal line. Tegmina completely developed or present as small scales. Alae absent, micropterous or brachypterous. Metanotum shorter than median segment. Meso- and metasternum with posteriorly, between legs, Y-shaped impression, antero-laterally resulting in two minute pseudo-foramina.

ABDomen. Abdominal segments slightly granulose and with fine median, longitudinal line. Tergum $\mathrm{X}$ with median, longitudinal carina, apically split into two semi-tergites. Inner apical rim of semi-tergites armed with several spines. Apex of semi-tergites obliquely pointing downwards. Posterolateral angles rounded. Poculum rounded, slightly projecting over apex of abdominal tergum IX. Apex of poculum narrower and rounded. No sclerotised vomer present. Cerci short, not reaching apex of tergum X, incurving, circular in cross-section, apices rounded.

Legs. Profemora slightly longer than head and thorax combined; compressed and curved basally. Anterodorsal carina with few, small serrations. 


\section{Female}

HEAD. Longer than wide, slightly tapering posteriorly and strongly granulose. Vertex elongated and with a shallow longitudinal impression. Dorsal portion of head flattened, with transverse, laterally acute ridge at posterior margin of eyes. Eyes circular and projecting hemispherically. Antennae short, with scapus strongly dorso-ventrally flattened and with lateral margins rounded. Apical half with very short segments.

Thorax. Pronotum shorter than head and granulose. Anterior margin incurved and raised, followed by median longitudinal impression, not reaching posterior margin. Transverse impression in middle, not reaching lateral edges of pronotum. Mesonotum granulose, with fine median longitudinal line. Metanotum with anterior margin weakly incurved and raised, longer than wide and strongly granulose. Meso- and metasternum as in male.

Abdomen. Terga granulose, with fine median, longitudinal line. Tergum $\mathrm{X}$ with median, longitudinal carina; notched posteriorly; posterolateral angles rounded. Epiproct elongated. Subgenital plate slightly elongated, just projecting over apex of tergum $\mathrm{X}$ and with median longitudinal carina; apex acute. Cerci short, not reaching apex of tergum X. Gonapophyses VIII elongated, reaching apex of epiproct.

Legs. Profemora longer than head, pronotum and mesonotum combined; compressed and curved basally. Anterodorsal carina with small serrations. Mesofemora with posterodorsal carina, with two to three lobes, anterior one being most prominent. Protibiae longer than head and thorax combined. Mesotibiae slightly longer than mesofemora. Metatibiae shorter than profemora.

\section{Distribution}

Currently known from different localities in Central and South Vietnam (see map Fig. 1).

\section{Species included and distribution}

Lobofemora bachmaensis sp. nov. [Bach Ma National Park]

Lobofemora bidoupensis sp. nov. [Bidoup Nui Ba National Park]

Lobofemora scheirei sp. nov. [Cat Tien National Park and Dong Nai Biosphere Reserve]

\section{Keys to the species of Lobofemora gen. nov.}

\section{Males}

1. Alae developed, projecting over posterior margin of median segment (Fig. 6D, H)

- Alae scale-like or absent (Figs 2D, H; 4D, H).

L. scheirei sp. nov.

2. Tegmina scale-like, flattened, just projecting over anterior margin of metanotum; alae absent (Fig. 2D, H); posterodorsal carina of mesotibiae with conspicuous triangular tooth (Fig. 2B) ....

L. bachmaensis sp. nov.

- Tegmina reaching halfway along metanotum, convex; alae scale-like (Fig. 4D, H); posterodorsal carina of mesotibiae unarmed (Fig. 4B) ..... L. bidoupensis sp. nov.

\section{Females}

1. Mesofemora with two lobes on posterodorsal carina: more basal one prominent; more apical one present as subapical triangular spine (Fig. 3D); vertex projecting posteriorly, almost reaching halfway along pronotum length (Fig. 3E, I) .

L. bachmaensis sp. nov.

- Mesofemora with three lobes on posterodorsal carina: most basal one most prominent and gradually becoming smaller; most apical one present as subapical triangular spine (Figs 5D, 7D); vertex rounded or slightly elongated posteriorly, not surpassing $1 / 3$ of pronotum length (Figs 5E, I; 7E, I) 
2. Posterodorsal carina of profemora armed with two enlarged triangular bispinose teeth; medioventral carina of metatibiae armed with two small triangular lobes anteriorly (Fig. 5D); vertex rounded posteriorly (Fig. 5E, I)

L. bidoupensis sp. nov.

- Posterodorsal carina of profemora unarmed; medioventral carina of metatibiae without triangular lobes anteriorly (Fig. 7D); vertex slightly elongated posteriorly (Fig. 7E, I)....... L. scheirei sp. nov.

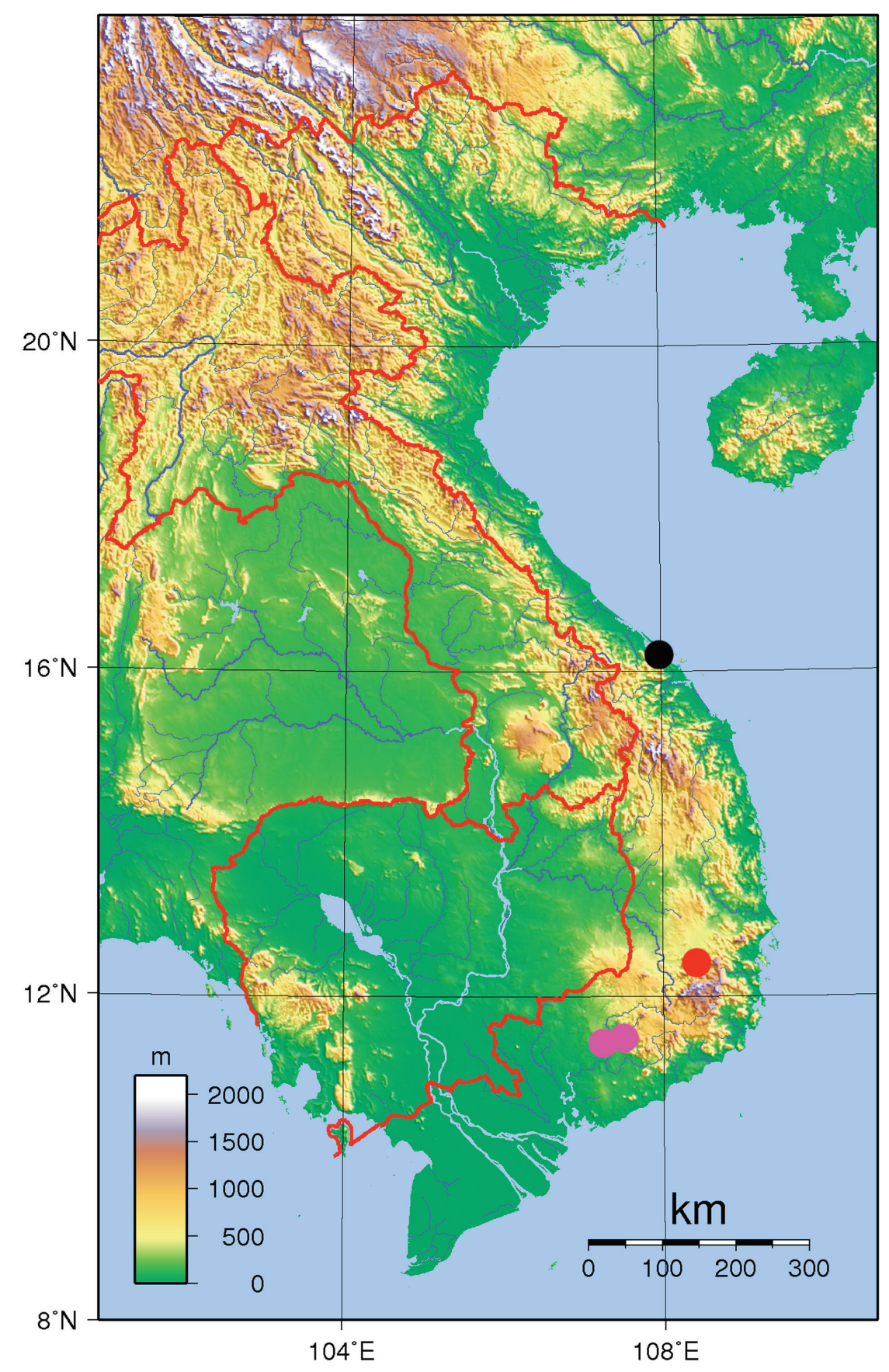

Lobomedaura bachmaensis sp. nov.

Lobomedaura bidoupensis sp. nov.

- Lobomedaura scheirei sp. nov.

Fig. 1. Distribution map of the species of Lobofemora gen. nov. 


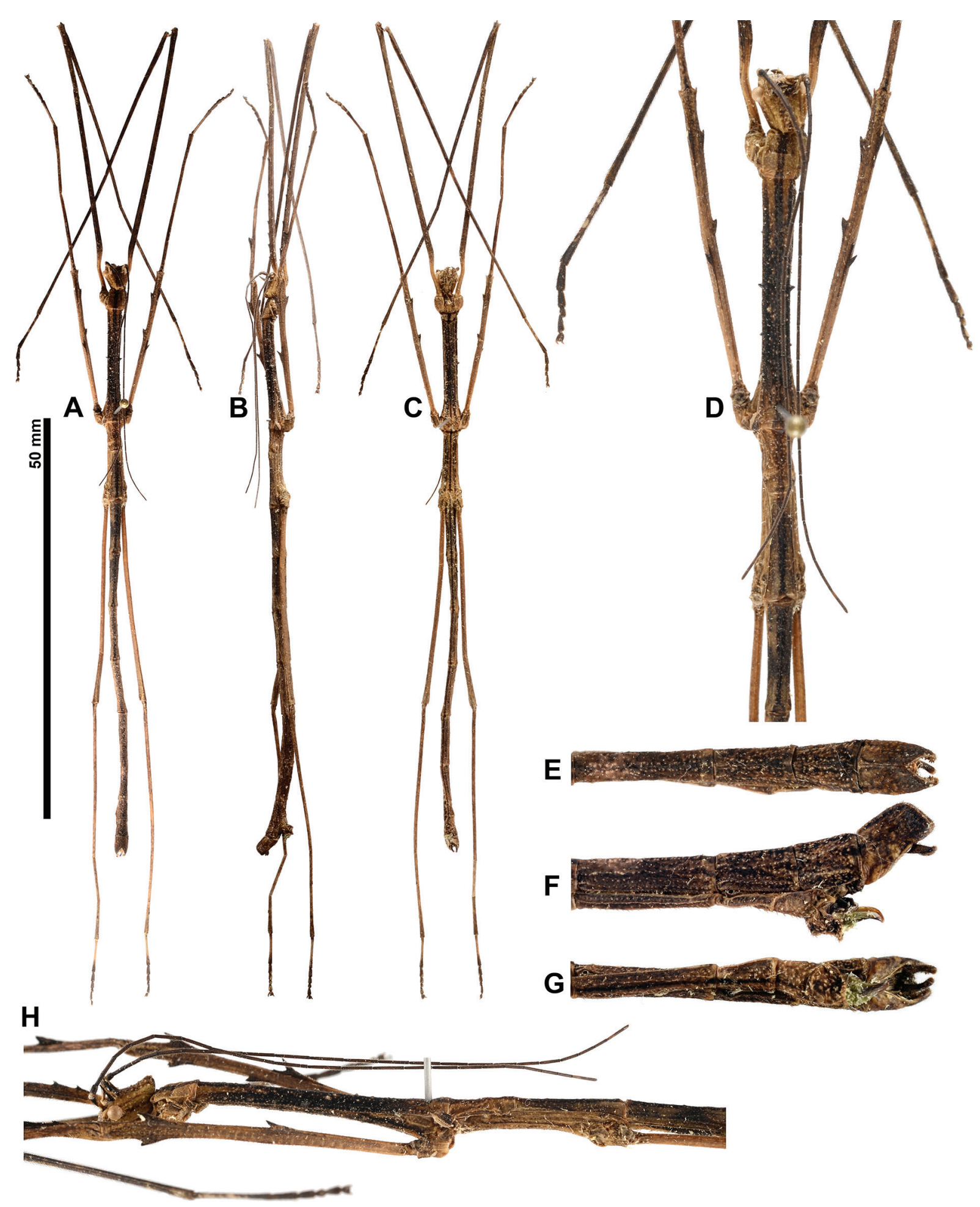

Fig. 2. Lobofemora bachmaensis sp. nov. Ō, holotype. A. Habitus, dorsal view. B. Habitus, lateral view. C. Habitus, ventral view. D. Anterior part of body, dorsal view. E. Apex of abdomen, dorsal view. F. Apex of abdomen, lateral view. G. Apex of abdomen, ventral view. H. Anterior part of body, lateral view. $\mathrm{D}-\mathrm{H}=$ not to scale. 


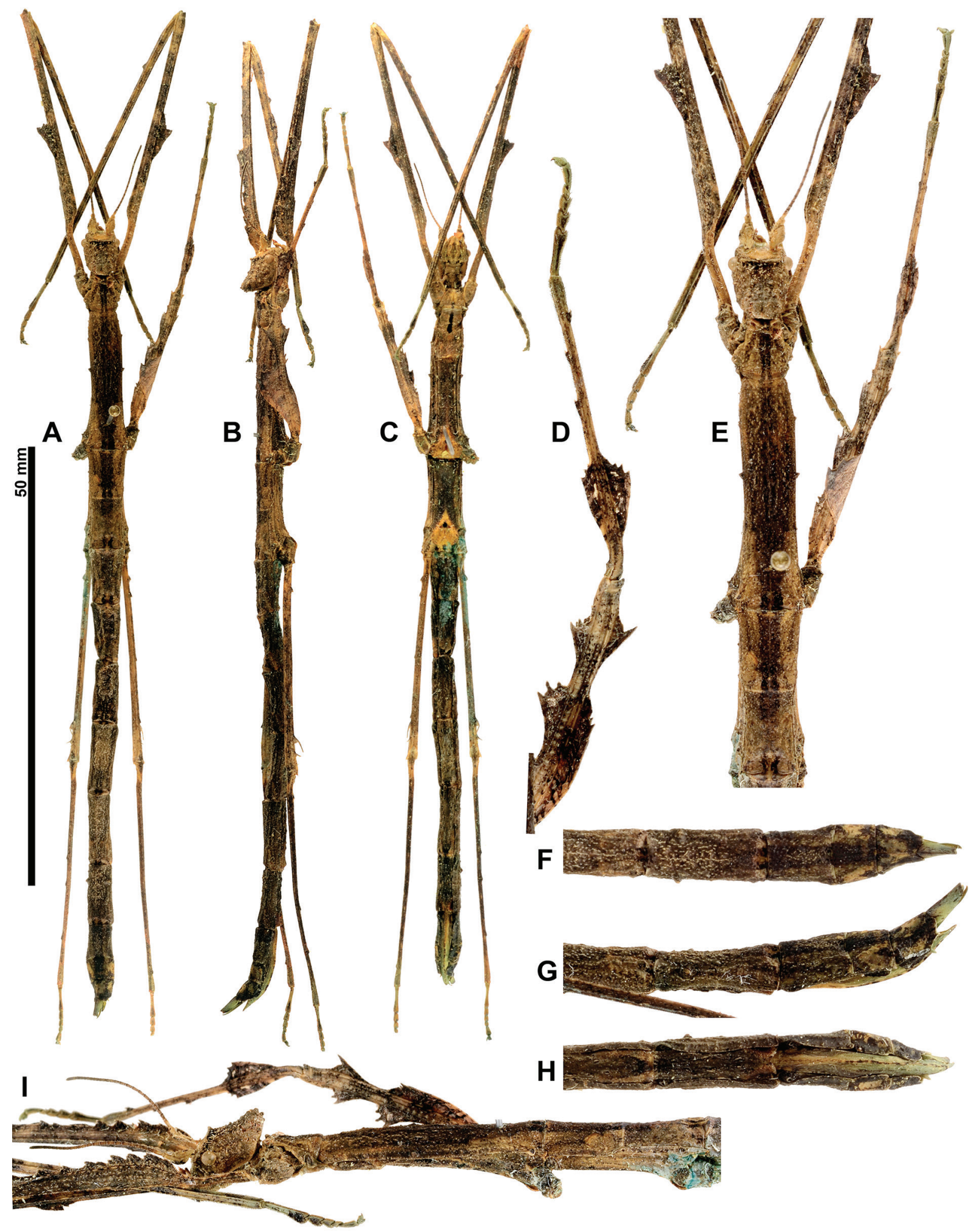

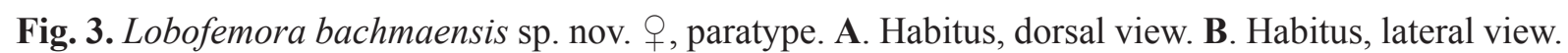
C. Habitus, ventral view. D. Right median leg, detail. E. Anterior part of body, dorsal view. F. Apex of abdomen, dorsal view. G. Apex of abdomen, lateral view. H. Apex of abdomen, ventral view. I. Anterior part of body, lateral view. D-I = not to scale. 


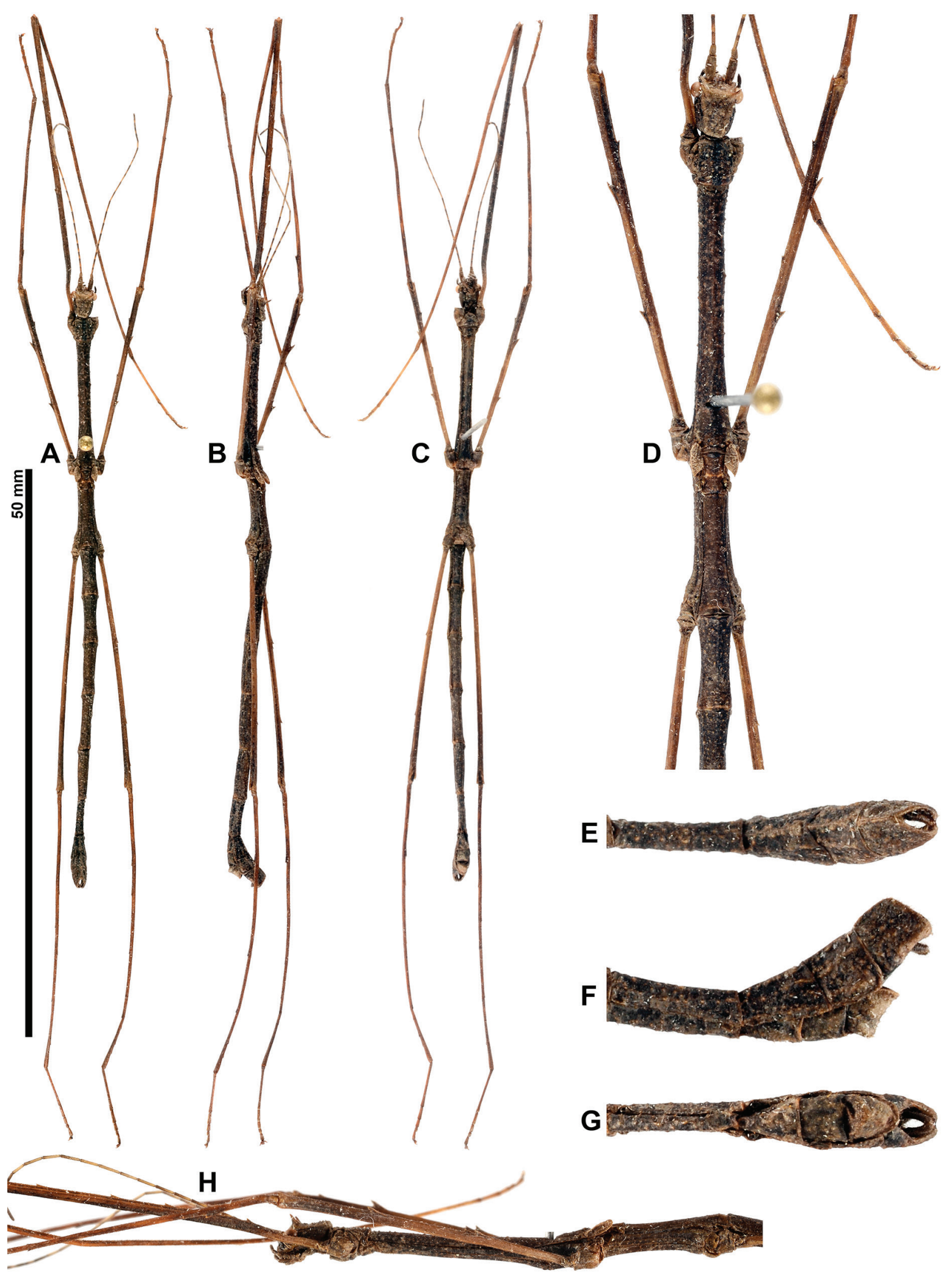

Fig. 4. Lobofemora bidoupensis sp. nov. ô, holotype. A. Habitus, dorsal view. B. Habitus, lateral view. C. Habitus, ventral view. D. Anterior part of body, dorsal view. E. Apex of abdomen, dorsal view. F. Apex of abdomen, lateral view. G. Apex of abdomen, ventral view. H. Anterior part of body, lateral view. $\mathrm{D}-\mathrm{H}=$ not to scale. 


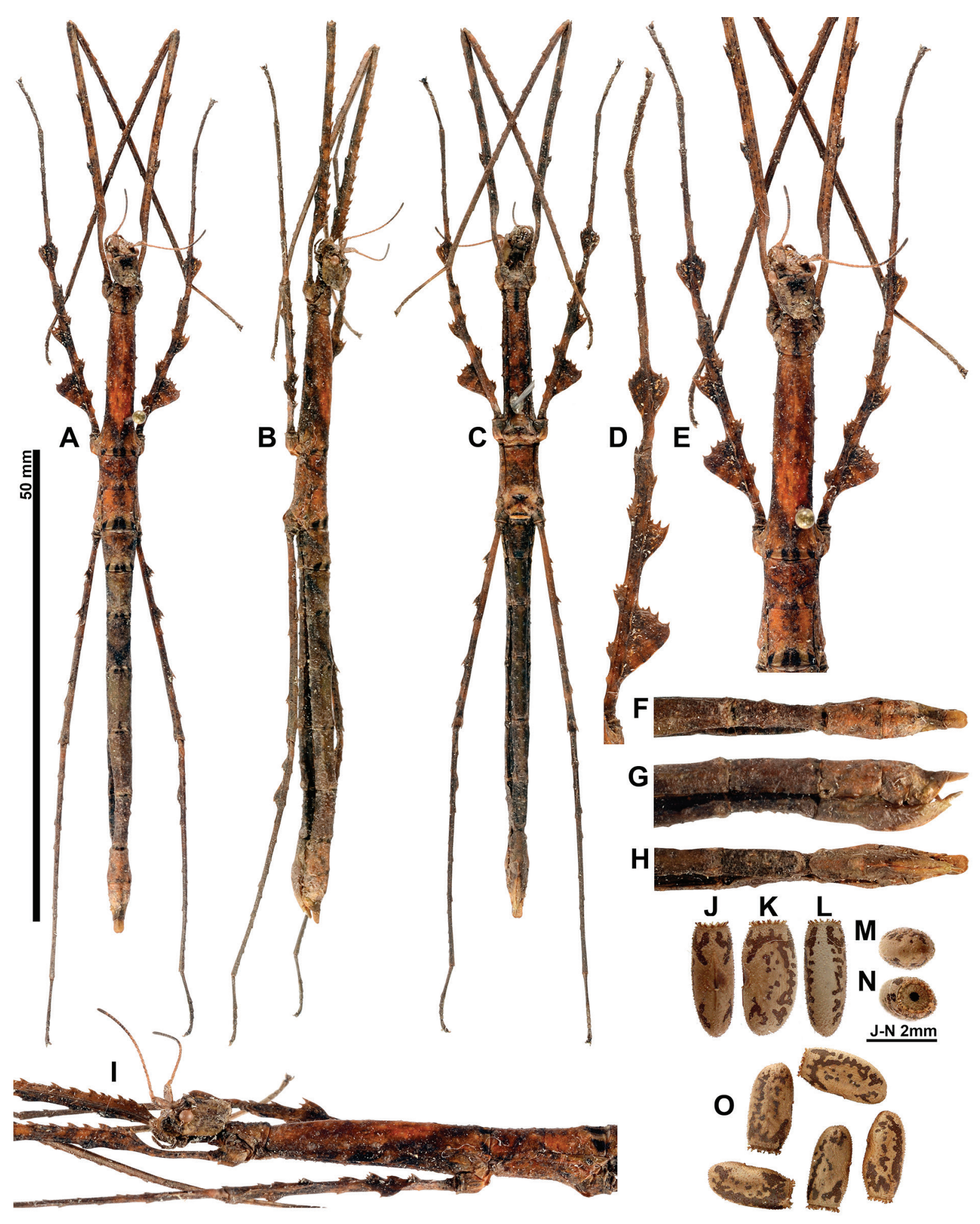

Fig. 5. Lobofemora bidoupensis sp. nov. A-I. + , paratype. A. Habitus, dorsal view. B. Habitus, lateral view. C. Habitus, ventral view. D. Right median leg, detail. E. Anterior part of body, dorsal view. F. Apex of abdomen, dorsal view. G. Apex of abdomen, lateral view. H. Apex of abdomen, ventral view. I. Anterior part of body, lateral view. J-N. Egg. J. Detail of micropylar plate. K. Lateral view. L. Ventral view. M. Detail of polar area. N. Detail of operculum. O. Eggs. D-I, O = not to scale. 


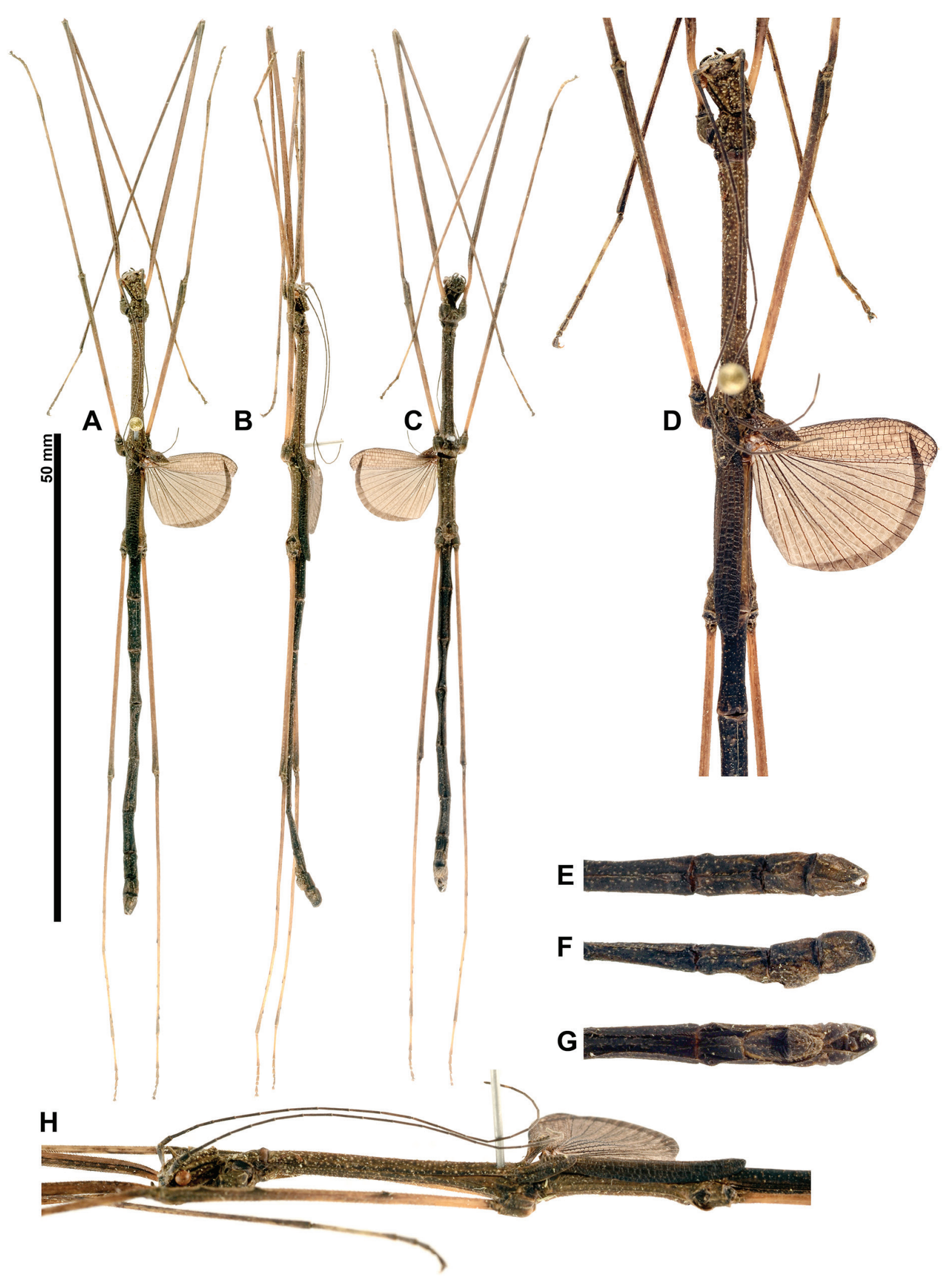

Fig. 6. Lobofemora scheirei sp. nov. $\widehat{\alpha}$, holotype. A. Habitus, dorsal view. B. Habitus, lateral view. C. Habitus, ventral view. D. Anterior part of body, dorsal view. E. Apex of abdomen, dorsal view. F. Apex of abdomen, lateral view. G. Apex of abdomen, ventral view. H. Anterior part of body, lateral view. $\mathrm{D}-\mathrm{H}=$ not to scale. 


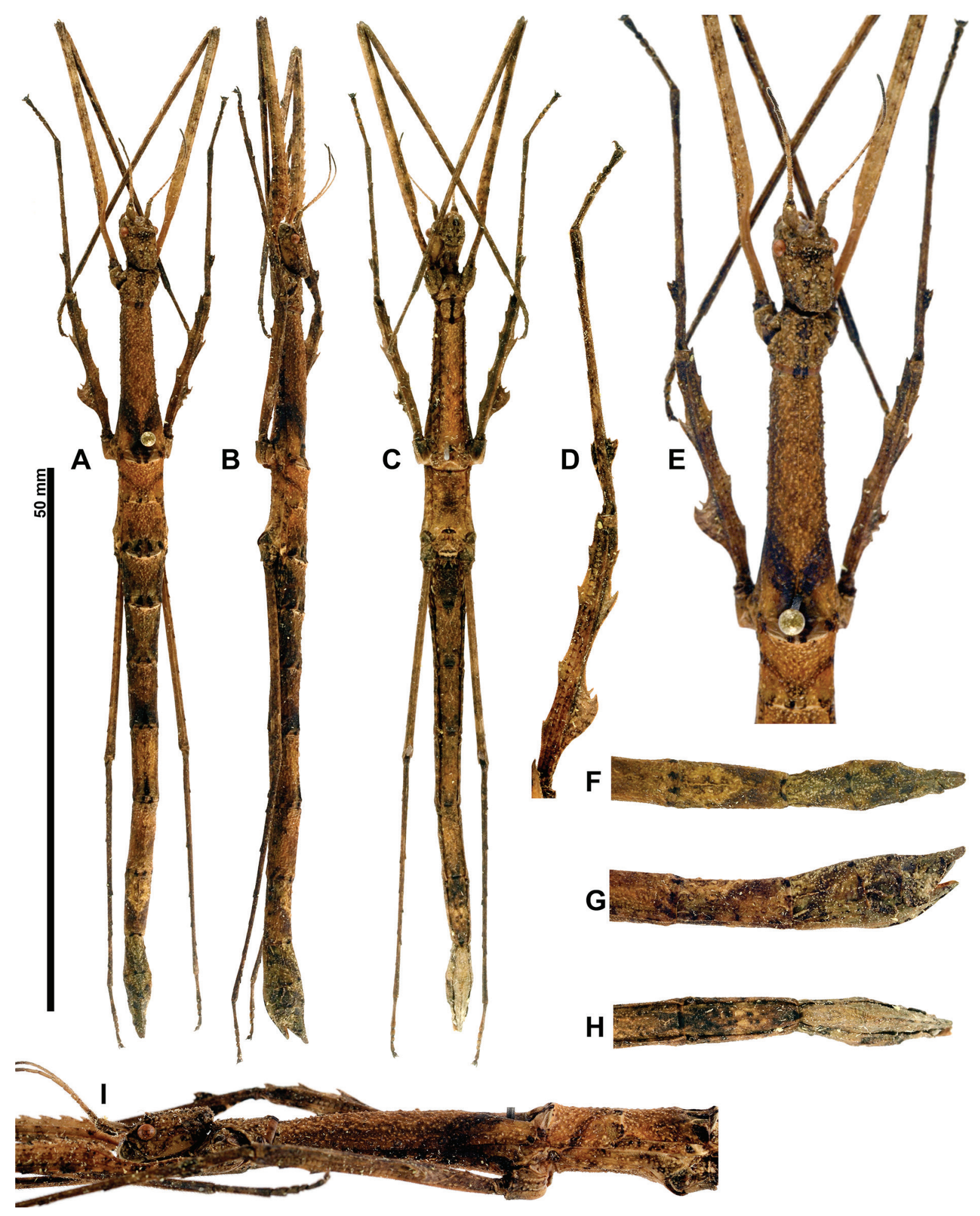

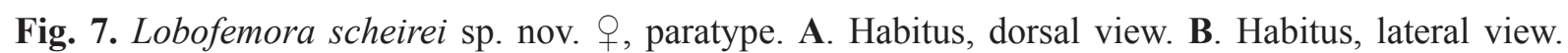
C. Habitus, ventral view. D. Right median leg, detail. E. Anterior part of body, dorsal view. F. Apex of abdomen, dorsal view. G. Apex of abdomen, lateral view. H. Apex of abdomen, ventral view. I. Anterior part of body, lateral view. D-I = not to scale. 
Lobofemora bachmaensis sp. nov. urn:Isid:zoobank.org:act:87AC14B9-A8A9-48E8-98C4-69A8A8162F67

Figs 1, 2, 3, 10A-C

\section{Etymology}

The species epithet refers to the type-locality, Bach Ma National Park in central Vietnam.

\section{Type material}

Holotype

VIETNAM: O̊: “Coll. I.R.Sc.N.B., C Vietnam, Bach Ma N.P., 16²12’N 10752’E, 12-17.vii.2011, leg. J. Constant \& J. Bresseel, I.G.: 31.933” (RBINS).

Paratypes $(1 \AA, 3 q q, 1 q$ nymph)

VIETNAM: same collection data as for holotype (RBINS; 1 §, 1 q : VNMN).

\section{Description}

Male (Fig. 2)

MeAsurements. See Table 1.

BoDy. Complete body more or less uniformly brown with blackish markings, sometimes with vague longitudinal darker line. Basitarsi and curved anterior part of profemora paler. Prosternum with conspicuous black, longitudinal median line.

HEAD. Longer than wide, slightly tapering posteriorly and granulose. Vertex elongated, projecting over anterior margin of pronotum. Dorsal portion of head flattened, with two definite spines projecting dorsally at posterior margin of eyes. Eyes circular and strongly projecting hemispherically. Antennae projecting over posterior margin of median segment, with 23 segments. Scapus strongly flattened dorsoventrally and laterally rounded. Pedicellus cylindrical.

THORAX. Pronotum almost rectangular and granulose, shorter than head and slightly widening posteriorly. Anterior margin incurved and raised, followed by faint, median longitudinal impression, not reaching posterior margin. Central transverse impression not reaching lateral edges of pronotum. Mesonotum about five times as long as pronotum and strongly granulose, widening posteriorly; three larger, spinose tubercles on each side, with largest one in middle; fine median longitudinal line. Tegmina with inner portion blackish and outer portion pale cream coloured, short, flattened and just projecting over anterior margin of metanotum; apically rounded. Alae absent. Metanotum with faint median line, shorter than median segment.

AвDomen. Abdominal segments II-V gradually increasing in length; V-VI about the same length, slightly granulose and with fine median, longitudinal line. Granules more concentrated along median line. Tergum VII shorter than tergum II. Tergum VIII about half as long as tergum II, slightly widening posteriorly. Tergum IX shorter than VIII and tectiform. Tergum X about as long as VIII and with median longitudinal carina; apically split into two semi-tergites. Inner apical rim of semi-tergite armed with several spines; apex obliquely pointing downwards. Posterolateral angles rounded. Poculum rounded, slightly projecting over apex of abdominal tergum IX. Apex of poculum narrower and rounded. Cerci short, not reaching apex of tergum $\mathrm{X}$, incurving, circular in cross-section, with apices rounded.

LEGS. Profemora slightly longer than head and thorax combined; compressed and curved basally. Anterodorsal carina with few, small serrations. Serrations mostly anteriorly. Other carinae unarmed. Mesofemora slightly shorter than head, pro- and mesonotum combined. Posterodorsal carina with two 
enlarged triangular spines, one central and one subapical. Anteroventral carina with single triangular subapical spine. Metafemora longer than mesofemora, but shorter than profemora. Protibiae longer than profemora and unarmed. Mesotibiae slightly longer than mesofemora. Posterodorsal carina with triangular spine in basal half. Anterodorsal carina with minute subapical spine. Ventral carinae unarmed. Metatibiae with minute saw-like spines in apical half on the outer carinae.

Female (Figs 3, 10A-C)

Measurements. See Table 1.

BoDy. Complete body more or less uniformly brown with blackish markings, sometimes with vague longitudinal darker line. Basitarsi and curved anterior part of profemora paler. Prosternum with conspicuous black, longitudinal median line.

HEAD. Longer than wide, slightly tapering posteriorly and strongly granulose. Vertex elongated, almost reaching halfway pronotum. Vertex with enlarged granules apically and asymmetrical: vertex split by shallow longitudinal impression, right hump slightly more pronounced than left one. Dorsal portion of head flattened, with transverse, laterally acute ridge at posterior margin of eyes. Eyes circular and projecting hemispherically. Antennae short, with 25 segments. Scapus strongly flattened dorso-ventrally and rounded laterally. Pedicellus slightly flattened dorso-ventrally. Apical half with very short segments, apical segment about as long as three preceding segments together. Genae granulose.

THorax. Pronotum trapezoidal, widening posteriorly; shorter than head and slightly granulose. Anterior margin incurved and raised, followed by median longitudinal impression, not reaching posterior margin. Central transverse impression not reaching lateral edges of pronotum. Mesonotum about four times as long as pronotum and strongly granulose, with fine median longitudinal line. Lateral edges with some larger blunt tubercles. Metanotum with anterior margin weakly incurved and raised, longer than wide and strongly granulose. Median segment 1.5 times longer than wide and granulose.

AвDOMEN. Abdominal segments II-VI gradually increasing in length, granulose and with fine median, longitudinal line. Tergum VII about as long as tergum II; sometimes with stalked, irregularly shaped tubercles. Tergum VIII shorter than tergum II, slightly widening posteriorly. Posterior margin weakly incurved. Tergum IX with anterior margin slightly convex, posterior margin slightly narrower and tectiform. Tergum X about as long as IX and with median, longitudinal carina; notched posteriorly and with posterolateral angles rounded. Epiproct elongated, slightly shorter than abdominal tergum $\mathrm{X}$ and with median, longitudinal carina; tectiform and apically rounded. Subgenital plate elongated, slightly projecting over apex of tergum $\mathrm{X}$, with median longitudinal carina; apex acute. Cerci short, not reaching apex of tergum X. Gonapophyses strongly elongated, reaching apex of epiproct.

LEGS. Profemora longer than head, pronotum and mesonotum combined; compressed and curved basally. Anterodorsal carina with small serrations, more prominent anteriorly. Posterodorsal carina indistinct with sometimes (two out of three specimens) an enlarged triangular lobe. Ventral carina present and unarmed. Mesofemora with postero-dorsal carina with two lobes; anterior one most prominent. Anterior lobe resulting in different spines; other lobe with one apical spine. Anteroventral carina with three lobes. Basal lobe less prominent and inconspicuous; median and subapical ones with several spines. Posteroventral carina with base more prominent and one subapical lobe. Metafemora with posterodorsal carina sparsely serrated with triangular spines. Posteroventral carina with small triangular lobe basally and with two spines subapically; the latter strongly elongated and "wire"-like (absent in one of the females). Protibiae longer than head and thorax combined. Dorsal carina with small, inconspicuous triangular lobes. Mesotibiae about as long as mesofemora. Posterodorsal carina with conspicuous lobe basally; anterodorsal carina with minute triangular spine near apex. Medioventral carina with conspicuous lobe mirroring the one on posterodorsal carina, and with minute black serrations. Metatibiae shorter than 
Table 1. Measurements (mm) of Lobofemora bachmaensis sp. nov. HT = holotype; $\mathrm{PT}=$ paratype(s).

\begin{tabular}{|c|c|c|c|}
\hline & HT $\hat{0}$ & PT $ㅇ ㅇ$ & PT $\hat{~} \lambda$ \\
\hline Body & 74.0 & $87.3-95.5$ & 69.2 \\
\hline Head & 4.1 & $6.5-7.5$ & 3.6 \\
\hline Pronotum & 2.4 & $3.6-4.2$ & 2.8 \\
\hline Mesonotum & 14.0 & $15.3-16.6$ & 12.8 \\
\hline Metanotum & 3.7 & $5.5-6.0$ & 3.7 \\
\hline Median segment & 6.2 & $5.8-6.2$ & 6.0 \\
\hline Profemora & 34.8 & $31.6-32.1$ & 29.6 \\
\hline Mesofemora & 17.1 & $16.2-17.0$ & 16.3 \\
\hline Metafemora & 24.5 & $22.9-25.1$ & 22.3 \\
\hline Protibiae & 39.7 & $35.5-36.7$ & 30.9 \\
\hline Mesotibiae & 18.4 & $16.7-17.6$ & 19.2 \\
\hline Metatibiae & 29.4 & $27.3-28.2$ & 27.0 \\
\hline Tegmina & 0.8 & - & \\
\hline
\end{tabular}

profemora; posteroventral carina with few triangular serrations; posterodorsal carina with subapical triangular spine.

Egg
Unknown.

\section{Distribution}

So far only known from Bach Ma National Park in central Vietnam (Fig. 1).

Lobofemora bidoupensis sp. nov. urn:Isid:zoobank.org:act:BA44BAFF-F44A-4476-ABF5-536CADC27B0E

Figs 1, 4, 5, 8, 10D-G

\section{Etymology}

The species epithet refers to the type-locality, Bidoup-Nui Ba National Park in central Vietnam.

\section{Type material}

\section{Holotype}

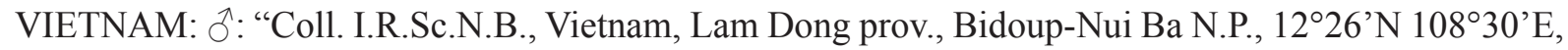
21-25.vii.2014, night coll., Leg. J. Constant \& J. Bresseel, GTI Project, I.G.: 32.779” (RBINS).

\section{Paratypes $(10 \hat{\partial}, 4$ q $ᄋ$ )}

VIETNAM: $6 \hat{\jmath}, 1$ q : same collection data as for holotype (RBINS); $4 \hat{\jmath}, 3 q q$ : “Coll. I.R.Sc.N.B., ex breeding J. Bresseel 2015, origin: Vietnam, Lam Dong prov., Bidoup-Nui Ba N.P., $12^{\circ} 26^{\prime} \mathrm{N} 108^{\circ} 30^{\prime}$ E, 21-25.vii.2014, J. Constant \& J. Bresseel, GTI Project, I.G.: 32.779” (RBINS; 1 ठ̊, 1 q: VNMN).

\section{Description}

Male (Figs 4, 8F-G, 10D)

MeAsurements. See Table 2.

BoDy. Base of femora pale brown, darkening towards apex. Tibiae mottled black and pale brown. Head with dorsal surface pale brown. Body darker brown with some black markings. 
HeAD. Longer than wide, slightly tapering posteriorly and granulose. Vertex slightly elongated. Dorsal portion of head flattened with two spines projecting dorsally at posterior margin of eyes. Eyes circular and strongly projecting hemispherically. Antennae with 21 segments. Scapus strongly flattened dorsoventrally and rounded laterally. Pedicellus cylindrical. Upper part of genae granulose.

Thorax. Pronotum longer than wide, almost rectangular and granulose, shorter than head; anterior margin incurved, followed by median longitudinal impression not reaching posterior margin; short, central, transverse impression not reaching lateral edges of pronotum. Mesonotum about six times as long as pronotum and strongly granulose, widening posteriorly, with fine median longitudinal line. Tegmina brown, short and slightly tapering posteriorly, not projecting over metanotum. Alae present as small scales, brown.

AвDomen. Abdominal segments II-V gradually increasing in length, V-VI about the same length, slightly granulose. Tergum VII shorter than tergum III. Tergum VIII about half as long as tergum II, slightly widening posteriorly. Tergum IX shorter than VIII and tectiform. Tergum X about as long as VIII and with median longitudinal carina; apically split into two semi-tergites. Inner apical rim of semi-tergite armed with several spines. Apex of semi-tergites obliquely pointing downwards; posterolateral angles rounded. Poculum rounded, slightly projecting over apex of abdominal tergum IX. Apex of poculum narrower and rounded. Cerci short, not reaching apex of tergum X, cylindrical in cross-section, with apices rounded.

LeGs. Profemora slightly longer than head and thorax combined; compressed and curved basally; dorsal carinae with few, minute spines; ventral carinae unarmed. Mesofemora longer than pro- and mesonotum combined; posterodorsal carina with two triangular spines and minute spine subapically; other carinae with few minute spines. Metafemora longer than head, pro-, meso- and metanotum combined; posterodorsal carina with four minute spines. Protibiae longer than profemora and unarmed. Mesotibiae slightly longer than mesofemora; medioventral carina with conspicuous, small triangular lobe. Metatibiae with minute saw-like spines in apical half on all carinae; medioventral carina with conspicuous triangular spine in anterior half.

Female (Figs 5, 8A-E, 10E-G)

Measurements. See Table 2.

BoDy. Complete body ranging from uniformly brown to mottled brown-black with some green and white markings. Prosternum with conspicuous black, longitudinal line.

HEAD. Longer than wide, slightly tapering posteriorly and granulose. Vertex slightly elongated and slightly asymmetrical: vertex split by shallow longitudinal impression; right portion slightly more pronounced than left one. Dorsal portion of head flattened, with transverse, laterally acute ridge at posterior margin of eyes; ridge split centrally by longitudinal depression. Eyes circular and projecting hemispherically. Antennae short with 24-26 segments. Scapus strongly flattened dorso-ventrally and rounded laterally, with outer lobe more prominent. Pedicellus slightly cylindrical; first antennomere about as long as the following two segments combined. Apical half with very short segments; apical segment about as long as four preceding segments combined. Upper part of genae tuberculate.

THORAX. Pronotum trapezoidal, widening posteriorly; shorter than head and granulose. Anterior margin incurved and raised, followed by median longitudinal impression not reaching posterior margin. Central transverse impression not reaching lateral edges of pronotum. Mesonotum about four times as long as pronotum and strongly granulose, slightly widening posteriorly, with fine median longitudinal line. Metanotum subquadrate with anterior margin weakly incurved and raised; strongly granulose and with median tubercle subapically. Median segment slightly longer than wide, anterior portion slightly 

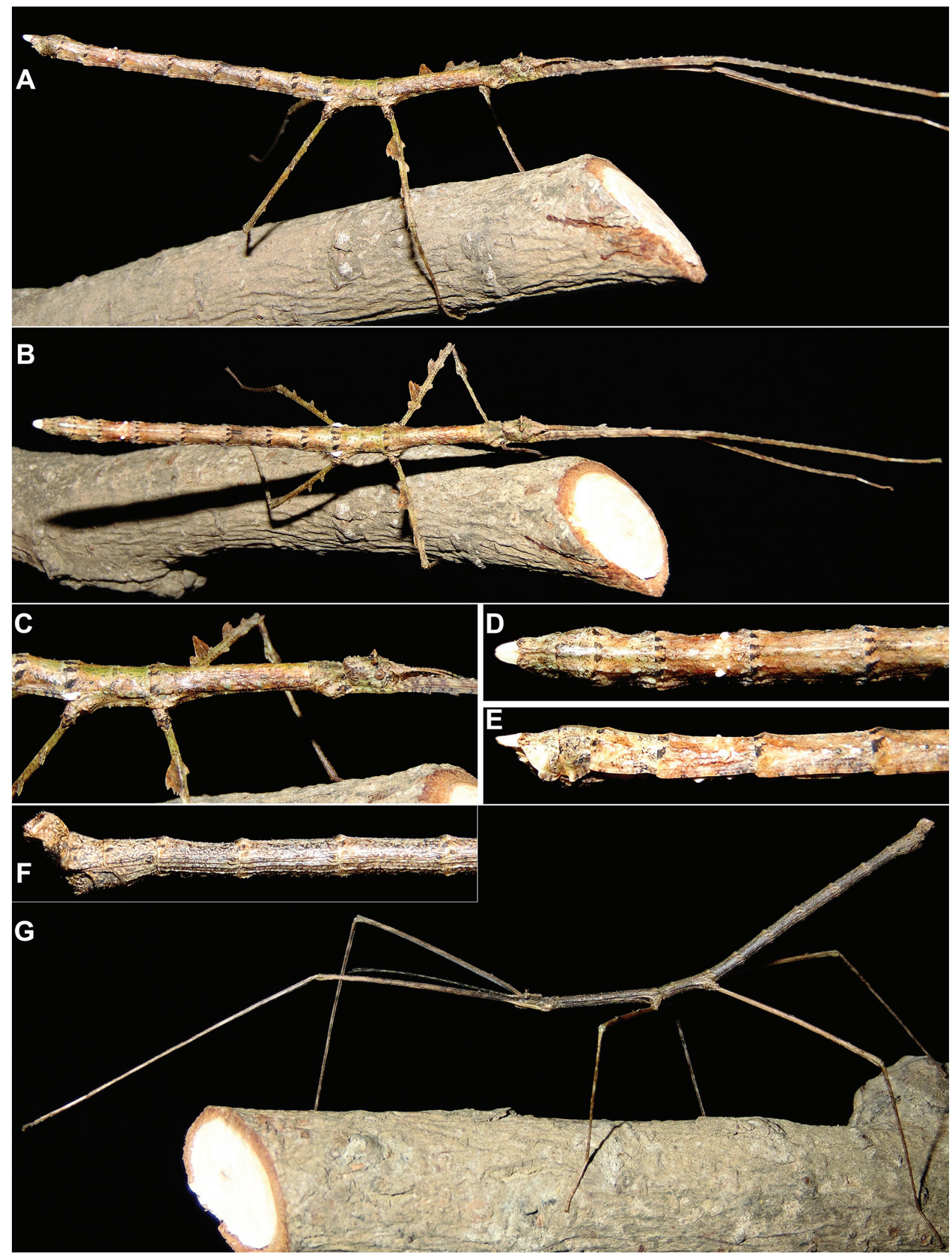

Fig. 8. Lobofemora bidoupensis sp. nov., captive reared specimens (photographs by the authors). A-E.. . A. Lateral view. B. Dorsal view. C. Anterior part of body, lateral view. D. Apex of abdomen, dorsal view. E. Apex of abdomen, lateral view. F-G. Ô. F. Apex of abdomen, lateral view. G. Lateral view. 
granulose. Mesosternum with posteriorly, between legs, Y-shaped impression resulting into two small pseudo-foramina. Metasternum with posteriorly, between legs, X-shaped impression resulting in two small pseudo-foramina anteriorly.

ABDomen. Abdominal segments II-V gradually increasing in length, granulose and with fine median, longitudinal line; larger granules along median line. Terga V-VI nearly equal in length. Tergum VII shorter than VI. Tergum VIII shorter than tergum VI, slightly widening posteriorly; posterior margin weakly incurved. Tergum IX with anterior margin slightly convex; posterior margin slightly narrower. Tergum X slightly longer than IX and with median, longitudinal carina; strongly notched posteriorly; posterolateral angles rounded. Terga IX-X with lateral edges more pronounced and lobe-like. Epiproct elongated; about $2 / 3$ as long as abdominal tergum $X$ and with very shallow apical notch. Subgenital plate elongated, slightly projecting over apex of tergum X; apical half with median longitudinal carina; apex rounded. Cerci short, not reaching of apex tergum X, cylindrical in cross-section, with apices rounded. Gonapophyses strongly elongated, reaching apex of epiproct.

Legs. Profemora longer than head, pro-, meso- and metanotum combined; compressed and curved basally; anterodorsal carina with small serrations, more prominent anteriorly; posterodorsal carina armed with two enlarged triangular bispinose teeth; posteroventral carina sometimes with few serrations anteriorly. Mesofemora with postero-dorsal carina with three definite lobes; anterior one most prominent and gradually becoming smaller; anterior and central lobes resulting in different spines; other lobe with one apical spine; anterodorsal carina with few, small triangular lobes resulting in different minute spines; anteroventral carina with three small lobes resulting in minute spines. Posteroventral carina with one small lobe in apical half. Metafemora with posterodorsal carina armed with four triangular spines resulting in minute small spines; anterodorsal carina sometimes with some minute spines; posteroventral carina with few small spines. Protibiae about as long as head and thorax combined; posterodorsal carina with few inconspicuous triangular lobes; anterodorsal carina with small serrations over its complete length; posteroventral carina with few minute spines. Mesotibiae slightly longer than mesofemora; posterodorsal carina with conspicuous lobe anteriorly and few small serrations posteriorly; medioventral carina with conspicuous lobe mirroring the one on posterodorsal carina and with minute black serrations; other carinae with few, small serrations. Metatibiae shorter than profemora; dorsal carinae and postero- and anteroventrally with minute serrations; medioventral carina armed with two small triangular lobes basally.

Egg (Fig. 5J-O)

MEASUREMENTS (in mm). Length: 3.0-3.5; width: 1.2; height: 1.5 .

Elongate-oval, general colouration, light brown with black patches. Capsule oval in cross section, with the surface granulose. Anteriorly with short brown fringes along the anterior margin of the capsule. Dorsal side slightly concave. Micropylar plate more or less inverted heart shaped, with a median impression posteriorly. Anteriorly triangular, then widening, posterolateral angles only slightly projecting over micropylar cup. Micropylar cup definite, followed by relatively long median line. Micropylar plate and median line coloured as capsule. Ventral side slightly convex. Polar area with shallow indention. Operculum slightly darker than capsule, with central dark, circular marking.

\section{Distribution}

So far only known from Bidoup-Nui Ba National Park in central Vietnam (Fig. 1). 
Table 2. Measurements ( $\mathrm{mm})$ of Lobofemora bidoupensis sp. nov. HT = holotype; $\mathrm{PT}=$ paratype(s).

\begin{tabular}{|c|c|c|c|}
\hline & HT 0 & PT $q$ 우 & PT 0 \\
\hline Body & 52.5 & $71.2-77.8$ & 55.0 \\
\hline Head & 2.7 & $4.5-4.7$ & 2.7 \\
\hline Pronotum & 1.8 & $2.6-2.7$ & 2.0 \\
\hline Mesonotum & 11.2 & $13.6-16.4$ & 11.7 \\
\hline Metanotum & 1.8 & $3.6-3.9$ & 2.5 \\
\hline Median segment & 4.7 & $4.3-4.4$ & 4.4 \\
\hline Profemora & 26.3 & $25.1-29.2$ & 28.2 \\
\hline Mesofemora & 15.8 & $15.8-15.5$ & 16.9 \\
\hline Metafemora & 20.3 & $21.3-24.5$ & 21.5 \\
\hline Protibiae & 31.1 & $30.1-33.1$ & 33.8 \\
\hline Mesotibiae & 17.8 & $16.6-18.4$ & 19.3 \\
\hline Metatibiae & 25.0 & $25.3-27.0$ & 27.1 \\
\hline Tegmina & 1.4 & - & \\
\hline
\end{tabular}

Lobofemora scheirei sp. nov.

urn:1sid:zoobank.org:act:9CE86F8D-E644-4A37-A278-DB4D99971378

Figs 6, 7, 9, 10H-J

\section{Etymology}

The species epithet refers to the Flemish TV show presenter Mr Lieven Scheire. We dedicate this new species to Lieven both in recognition of his efforts in raising public awareness of science (including taxonomy), especially for young people, in his TV shows, and as a present for his recent wedding.

\section{Type material}

\section{Holotype}

VIETNAM: §̊: “Coll. I.R.Sc.N.B., Vietnam, Dong Nai Biosphere Res. $11^{\circ} 18^{\prime}$ N 107º6’E, 25.vi-6. vii.2012, night collecting, Leg. J. Constant \& J. Bresseel, I.G.: 32.161” (RBINS).

Paratypes (39 $\widehat{\jmath}, 28 q q, 17$ eggs)

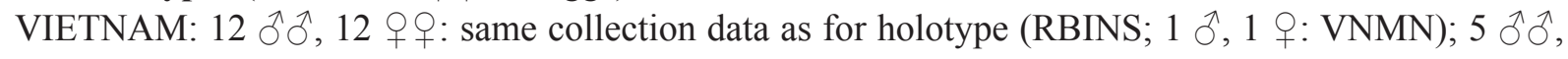
5 우: “Coll. I.R.Sc.N.B., Vietnam, Cat Tien N.P., $11^{\circ} 26^{\prime}$ N $107^{\circ} 26^{\prime}$ E, 6-16.vii.2012, Leg. J. Constant \& J. Bresseel, I.G.: 32.161" (RBINS; 1 §, 1 O :VNMN); 12 eggs: "Coll. I.R.Sc.N.B., ex breeding J. Bresseel i.2015, origin: Vietnam, Cat Tien N.P., $11^{\circ} 26^{\prime} \mathrm{N} 107^{\circ} 26$ 'E, 6-16.vii.2012, J. Constant \& J. Bresseel” (RBINS; 2: VNMN); 22 $\widehat{\jmath}, 11$ 우우, 5 eggs: "Ex culture F. Hennemann 2015, Origin: S-Vietnam, Lam

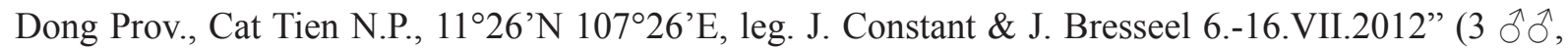

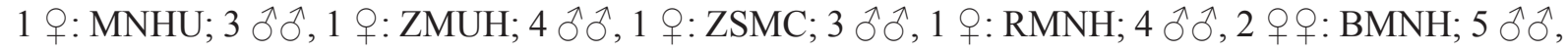
5 우우, 5 eggs: FHC).

\section{Additional material}

VIETNAM: 25 ふふ઼, 23 우, 45 eggs: "Ex culture F. Hennemann 2015, Origin: S-Vietnam, Lam Dong Prov., Cat Tien N.P., 11²6’N 107²6’E, leg. J. Constant \& J. Bresseel 6-16.VII.2012”' (FHC).

\section{Description}

Male (Figs 6, 9I-M, 10H)

MeAsurements. See Table 3. 
Body. Complete body blackish-brown. Profemora dark brown, paler basally. Protibiae light brown. Other femora pale brown with darker apex. Corresponding tibiae pale brown.

HEAD. Longer than wide, slightly tapering posteriorly and granulose. Vertex slightly elongated. Dorsal portion of head flattened, with two spines projecting dorsally at posterior margin of eyes. Eyes circular and strongly projecting hemispherically. Antennae almost reaching posterior margin of median segment, with 23 segments. Scapus strongly flattened dorso-ventrally and rounded laterally. Pedicellus cylindrical. Upper part of genae granulose.

THORAX. Pronotum trapezoidal and granulose, widening posteriorly; shorter than head; anterior margin incurved and raised, followed by median longitudinal impression not reaching posterior margin. Central transverse impression not reaching lateral edges of pronotum. Mesonotum about six to seven times as long as pronotum and strongly granulose, widening posteriorly; with fine median longitudinal line. Tegmina blackish, short and with definite hump; slightly tapering posteriorly and with apex rounded; external margin densely covered with minute tubercles. Alae projecting over apex of median segment; costal area coloured as elytra, anal area greyish brown; subcostal and radial veins densely covered with minute tubercles.

ABDomen. Abdominal segments II-V gradually increasing in length, V-VI about equal in length, slightly granulose and with fine median, longitudinal line; granules more concentrated along median line. Tergum VII shorter than tergum III. Tergum VIII about half as long as tergum II, slightly widening posteriorly. Tergum IX shorter than VIII and tectiform. Tergum X about as long as VIII and with median longitudinal carina; apically split into two semi-tergites. Inner apical rim of semi-tergite armed with several spines; apex obliquely pointing downwards; posterolateral angles rounded. Poculum rounded, slightly projecting over apex of abdominal tergum IX. Apex of poculum narrower and rounded. Cerci short, not reaching apex of tergum $\mathrm{X}$, cylindrical in cross-section, with apices rounded.

Legs. Profemora slightly longer than head and thorax combined; compressed and curved basally; anterodorsal carina with few, small serrations anteriorly; other carinae unarmed. Mesofemora about as long as pro- and mesonotum combined; posterodorsal carina variably with few triangular spines. Metafemora longer than head, pro-, meso- and metanotum combined and unarmed. Protibiae longer than profemora and unarmed. Mesotibiae slightly longer than mesofemora; anterodorsal carina with minute subapical spine; anteroventral carina with minute spine situated more basally than spine on anterodorsal carina; posteroventral carina with minute spine more basally than spine on anteroventral carina. Metatibiae with minute saw-like spines in posterior half on all carinae.

Female (Figs 7, 9A-H, 10I-J)

MEASUREMENTS. See Table 3.

Body. Colouration variable. Most specimens more or less uniformly brown with some black markings; some specimens with head, legs and apex of abdomen red-brown and very pale fawn body. Prosternum with conspicuous black, longitudinal median line.

HEAD. Longer than wide, slightly tapering posteriorly and granulose. Vertex slightly elongated and asymmetrical: vertex split by shallow longitudinal impression, right hump slightly more pronounced than left one. Dorsal portion of head flattened, with transverse, laterally acute ridge at posterior margin of eyes. Eyes circular and projecting hemispherically. Antennae short, with 23-25 segments, most females possess 25 segments. Scapus strongly flattened dorso-ventrally and rounded laterally, with outer lobe more prominent. Pedicellus slightly flattened dorso-ventrally. First antennomere about as long as following two ones combined. Apical half of antenna with very short segments; apical segment about as long as four preceding segments combined. Upper part of genae granulose. 


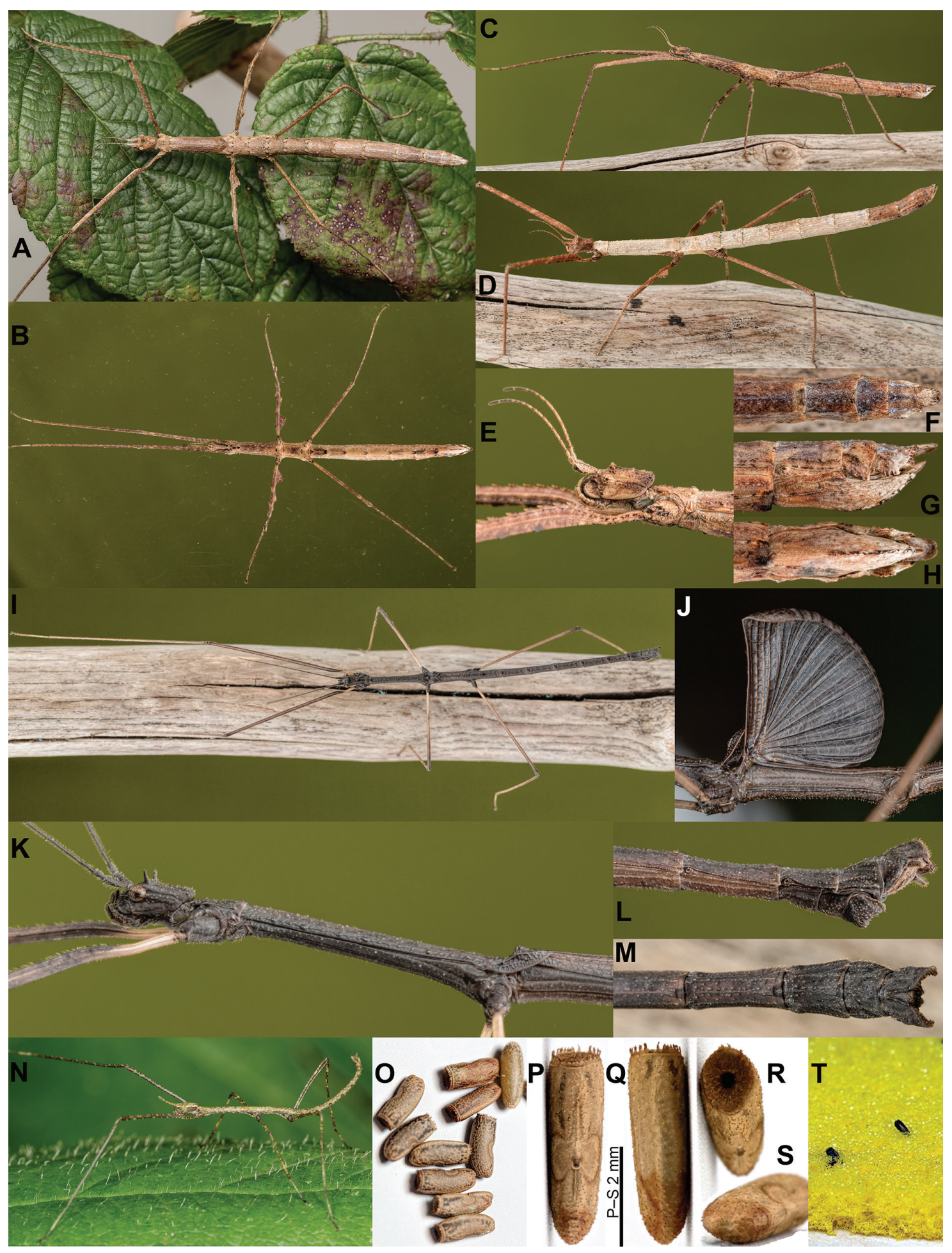

Fig. 9. Lobofemora scheirei sp. nov., captive reared specimens (photographs by Dr B. Kneubühler). A-H. . . A. Dorsal view. B. Ventral view. C. Lateral view. D. Dorsolateral view, morph whitish with head, apex of abdomen and legs chestnut brown. E. Head, lateral view. F. Apex of abdomen, dorsal view. G. Apex of abdomen, lateral view. H. Apex of abdomen, ventral view. I-M. §. I. Dorsal. J. Wing spread, lateral view. K. Head and thorax, lateral view. L. Apex of abdomen, lateral view. M. Apex of abdomen, dorsal view. N. Nymph. O. Eggs. P-S. Egg. P. Detail of micropylar plate. Q. Ventral view. R. Detail of operculum. S. Detail of polar area. T. Eggs laid in a slice of sponge. 

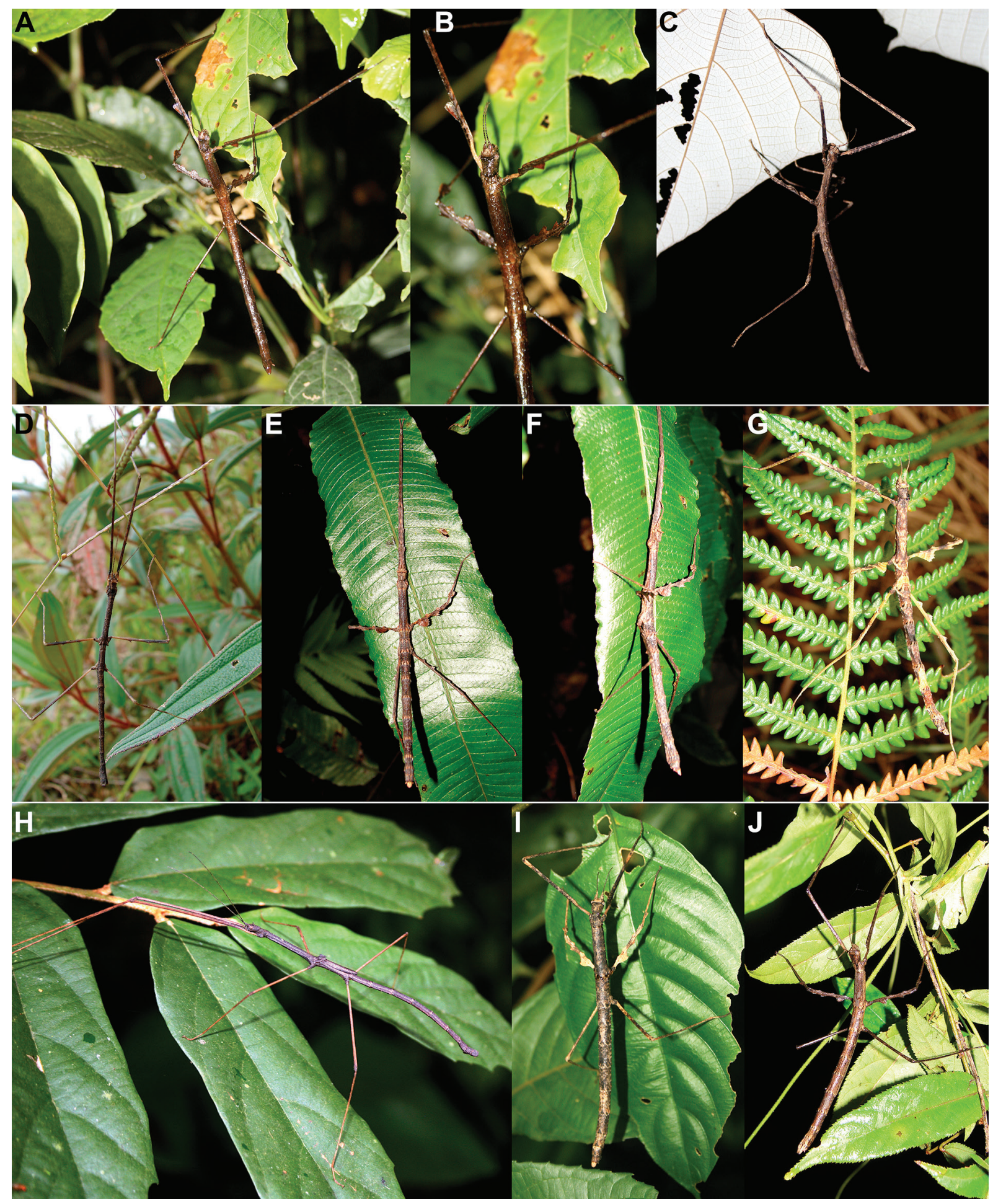

Fig. 10. Lobofemora gen. nov. spp., photographs in natura by the authors. A-C. L. bachmaensis sp. nov., Bach Ma National Park. A-B. + , 11 Jul. 2011. C. + , 14 Jul. 2011. D-G. L. bidoupensis sp. nov., BidoupNui Ba National Park. D. §̊, 22 Jul. 2014. E-F.,+ 25 Jul. 2014. G.,+ 23 Jul. 2014. H-J. L. scheirei sp. nov. H-I. Dong Nai Biosphere Reserve, 30 Jun. 2012. H. §. I. +. J. q, Cat Tien National Park, 9 Jul. 2012. 
Thorax. Pronotum trapezoidal, widening posteriorly; shorter than head and granulose; anterior margin incurved and raised, followed by median longitudinal impression not reaching posterior margin. Central transverse impression not reaching lateral edges of pronotum. Posterior margin with small posteromedian tubercle. Mesonotum about 3.7 times as long as pronotum and strongly granulose, widening posteriorly; fine median longitudinal line; tiny vestigial wing remnants posterolaterally. Metanotum with anterior margin weakly incurved and raised, subquadrate and strongly granulose. Median segment slightly longer than wide; anterior portion strongly granulose. Meso- and metasternum with posteriorly, between legs, Y-shaped impression resulting in two small pseudo-foramina.

ABDomen. Abdominal segments II-VI gradually increasing in length, granulose and with fine median, longitudinal line; larger granules along median line. Tergum VII about as long as tergum III; sometimes with stalked, irregularly shaped tubercles. Tergum VIII shorter than tergum II, slightly widening posteriorly; posterior margin weakly incurved. Tergum IX with anterior margin slightly convex; posterior margin slightly narrower. Tergum X about as long as IX and with median, longitudinal carina; strongly notched posteriorly; posterolateral angles rounded. Terga IX-X with lateral edges more pronounced and lobe-like. Epiproct elongated, about $2 / 3$ as long as abdominal tergum X, and with median, longitudinal carina; tectiform and with shallow apical notch. Subgenital plate elongated, slightly projecting over apex of tergum X; apical half with median longitudinal carina; apex rounded. Cerci short, not reaching apex of tergum X, cylindrical in cross-section, with apices rounded. Gonapophyses strongly elongated, reaching apex of epiproct.

Legs. Profemora longer than head, pronotum and mesonotum combined; compressed and curved basally; anterodorsal carina with small serrations, more prominent anteriorly; posterodorsal carina indistinct; posteroventral carina sometimes with few minute serrations. Mesofemora with three lobes on posterodorsal carina; anterior one most prominent and gradually becoming smaller; anterior lobe resulting in different spines; two other lobes with one apical spine; antero-ventral carina with three small lobe-like spines; posteroventral carina with one small lobe-like spine in apical half. Metafemora with anterodorsal carina sparsely serrated; other carinae unarmed. Protibiae longer than head and thorax combined; posterodorsal carina with inconspicuous triangular lobe positioned at about basal $1 / 4$ of length; anterodorsal carina with few minute serrations. Mesotibiae slightly longer than mesofemora; posterodorsal carina with conspicuous lobe at about basal $1 / 4$ of length; dorsal carinae with minute black spine near apex; medioventral carina with conspicuous lobe mirroring the one on posterodorsal carina and with minute black serrations; postero- and anteroventral carinae with minute black serrations. Metatibiae shorter than profemora; all ventral carinae with minute black serrations; dorsal carinae sparsely armed with minute black serrations, more concentrated subapically.

Nymph (Fig. 9N)

Newly hatched nymphs are about $17 \mathrm{~mm}$ long and have comparatively long legs. Antennae short, slightly longer than head. Body entirely mottled green, brown and black.

\section{Egg (Fig. 90-S)}

MEASUREMENTS (in mm). Length: 4.0; width: 1.2; height: 1.5 .

Elongate-oval, general colouration light brown with black markings. Capsule oval in cross section, with the surface granulose and with a net-like sculpturing. Anteriorly with short brown fringes along the anterior margin of the capsule. Dorsal side slightly concave. Micropylar plate more or less bi-lobate with a median impression anteriorly and posteriorly. Anteriorly triangular, then widening; lateral expansions axe-shaped, with posterolateral angles projecting over micropylar cup. Micropylar cup definite, blackish and followed by relatively long median line. Micropylar plate and median line coloured as capsule. 
Table 3. Measurements (mm) of Lobofemora scheirei sp. nov. HT = holotype; PT = paratypes.

\begin{tabular}{|l|c|c|c|}
\hline & HT $\delta^{\lambda}$ & PT $q$ $q$ & PT $\overbrace{}^{\lambda}$ \\
\hline Body & 66.5 & $72.3-79.9$ & $56.3-73.4$ \\
\hline Head & 3.3 & $5.4-5.5$ & $2.5-3.4$ \\
\hline Pronotum & 2.1 & $3.7-3.8$ & $1.9-2.1$ \\
\hline Mesonotum & 14.3 & $13.2-15.7$ & $11.1-14.8$ \\
\hline Metanotum & Covered by wings & $3.9-4.1$ & Covered by wings \\
\hline Median segment & Covered by wings & $4.2-4.9$ & Covered by wings \\
\hline Profemora & 30.0 & $24.6-26.9$ & $25.2-31.2$ \\
\hline Mesofemora & 17.1 & $15.0-16.0$ & $14.1-17.1$ \\
\hline Metafemora & 23.5 & $19.3-21.4$ & $18.8-22.2$ \\
\hline Protibiae & 36.0 & $30.9-31.6$ & $30.0-37.0$ \\
\hline Mesotibiae & 19.5 & $15.7-16.0$ & $16.0-19.2$ \\
\hline Metatibiae & 27.5 & $24.3-24.9$ & $23.2-27.6$ \\
\hline Tegmina & 2.8 & - & $1.9-2.9$ \\
\hline Alae & 9.4 & - & $8.5-9.5$ \\
\hline
\end{tabular}

Ventral side slightly convex. Polar area with shallow indention. Operculum slightly darker than capsule, with deep central impression.

\section{Distribution}

So far only known from Cat Tien National Park and Dong Nai Biosphere Reserve in south Vietnam (Fig. 1).

\section{Biological observations}

Several eggs of this species hatched and nymphs were reared in captivity using ferns (Dryopteridacea), which seem to be their natural foodplant. Substitute plants like bramble (Rubus L. spp., Rosaceae), beech (Fagus sylvatica L., Fagaceae) and Hypericum L. spp. (Hypericaceae) are also well accepted in captivity in Europe. This species is easy to maintain in captivity. Females try to stick their eggs into cracks and holes. Sponges cut into slices are suitable as substrate for this (Fig. 9T). Only few eggs will lay on the cage floor (pers. comm. B. Kneubühler, Jan. 2015). To collect eggs from wild caught females, paper tissue was used as substrate for egg laying.

Males are capable of stridulating, but in order to do so, they have to completely open their wings. When wings are open, the alae are not flat as in most stick insects, but have the outer margin curved downwards (Fig. 9J). By rubbing the outer margins of the tegmina against the subcostal and radial veins of the alae they are able to produce sound. The stridulation occurs when the specimens are disturbed.

\section{Discussion}

The currently known distribution of the genus Lobofemora gen. nov. is restricted to the southern half of Vietnam. The three new species were found at altitudes ranging from close to sea level (in Bach Ma National Park) up to 1600 m (in Bidoup-Nui Ba National Park).

From our observations in the field and in culture, it appears that the colouration in males is very constant, while females show more variable patterns and colours.

When identifying specimens of Lobofemora gen. nov., one must be aware that regenerated legs do not show the specific features of the "normal" specimens: lobes and spines are less developed and can even be absent. 
The tribal placement of Lobofemora gen. nov. suggested herein is based on a set of characters which key out to the tribe Clitumnini Brunner von Wattenwyl, 1893. This due to having shortened antennae, that are not longer than the profemora, with a considerably broadened scapus; profemora that are triangular in cross-section with the anterodorsal carina strongly raised and the medioventral carina conspicuously displaced towards the anteroventral carina; females with strongly elongated lower gonapophyses (gonapophyses VIII) which clearly project over the apex of the subgenital plate; eggs are elongate and bullet-shaped, with an open internal micropylar plate and a well developed median line and lacking a central capitulum. Furthermore, eggs have a hairy rim on the border of the capitulum. Males lack an external vomer.

However, as mentioned above the definition of the Clitumnini had to be adapted to include this genus. The genus actually shares and violates several morphological characters with both Clitumnini and Medaurini Hennemann \& Conle, 2008. Therefore, the genus has a fairly isolated position within the tribe.

The beak-like ovipositor is shared with several other genera in Clitumnini, e.g., Entoria Stål, 1875, Metentoria Brunner von Wattenwyl, 1907 and Rhamphophasma Brunner von Wattenwyl, 1893.

The aberrant and remarkable characters exhibited by Lobofemora gen. nov., with especially the length of the median segment and presence of tegmina and vestigial or shortened alae in the males, are unique within the entire tribe Clitumnini and warrant further investigation.

As usual for stick insects that have wings in one or both sexes, the median segment is fairly long in relation to the metanotum, an additional feature which distinguishes Lobofemora gen. nov. from all currently known genera of the tribe Clitumnini.

Traditionally, the presence of wings has a priori been regarded as a plesimorphic character, but Whiting et al. (2003) have shown that wings within the Phasmatodea can not only be lost but also recovered during the evolutionary process of certain clades, a hypothesis which is supported by several examples and has already received acceptance by certain subsequent authors (e.g. Hennemann \& Conle 2008). The decision on whether the presence of wings in the males of Lobofemora gen. nov. is plesiomorphic or apomorphic for the tribe Clitumnini is difficult to make at present and certainly warrants a detailed phylogenetic analysis of this and potentially closely related taxa. If it is regarded as an autapomorphy of Lobofemora gen. nov., this would be a further and very striking example for the recovery of wings in stick insects and support the hypothesis of Whiting et al. (2003), since all other known taxa of the very diverse and speciose tribe Clitumnini and also the related Medaurini are exceptionally wingless. Another fact that makes the presence of wings in Lobofemora gen. nov. even more remarkable is the capability of the winged males of $L$. scheirei sp. nov. to stridulate. This striking specialization is also not found in the winged males of the supposedly closely related tribe Pharnaciini (regarded as a subordinate taxon of the subfamily Clitumninae by Hennemann \& Conle 2008) and hence is unique in that entire subfamily. The sounds are produced by rubbing the tegmina against the radial and subcostal veins of the alae, which bear numerous very minute tooth-like structures. Morphologically this is an analogy to the wing structures, e.g., seen in certain winged taxa of the predominantly New Guinean genus Dimorphodes Westwood, 1859 (Phasmatidae: Xeroderinae: Xeroderini), members of the Mascarean tribe Achriopterini or the New World genus Pterinoxylus Audinet-Serville, 1838 (Cladomorphinae: Hesperophasmatini). It is hoped that future phylogenetic studies will deal with the interesting new genus described herein to clarify its taxonomic and phylogenetic position.

However, one must be aware that most genera in Clitumnini need to be redefined and several appear to be polyphyletic in their present configuration. For that reason, it is of utmost importance that DNAbased phylogenetic studies contain, for each genus, at least the type species to be well supported. 


\section{Acknowledgments}

We thank Dr Hong Thai Pham (VNMN), Mr Vu Tru Hoang and Mr Thieu Du Tran (Institute of Ecology and Biological Resources, Hanoi, Vietnam) for all their help and friendship during collecting trips, Dr Bruno Kneubühler (Luzern, Switzerland) for his excellent pictures and all his help in breeding the species we study, Mr Tim Bollens (Herselt, Belgium) for providing live specimens, Mr Ludovic Nicolas for mounting numerous specimens we brought back from the field and the authorities of the different national parks and reserves for their support to our studies. All the authors' collecting trips were supported through grants issued by the capacity building Programme of the Belgian Global Taxonomic Initiative National Focal Point that runs with financial support from the Belgian Directorate-General for Development Cooperation. Dr Patrick Grootaert, Dr Yves Samyn and Dr Marie-Lucie Susini (RBINS) are also thanked for their permanent support to our projects in Vietnam. We warmly thank Mr Frank Hennemann (Hohenecken, Germany) for his valuable comments, which greatly improved our work.

\section{References}

Brock P.D. 2015. Phasmida Species File Online. Version 5.0/5.0. Available from http://Phasmida. SpeciesFile.org [accessed 19 Jan. 2015]

Clark Sellick J.T. 1997. Descriptive terminology of the phasmid egg capsule, with an extended key to the phasmid genera based on egg structure. Systematic Entomology 22 (2): 97-122. http://dx.doi. org/10.1046/j.1365-3113.1997.d01-30.x

Clark Sellick J.T. 1998. The micropylar plate of the eggs of Phasmida, with a survey of the range of plate form within the order. Systematic Entomology 23 (3): 203-228. http://dx.doi.org/10.1046/j.1365$\underline{3113.1998 .00056 . x}$

Hennemann F.H. \& Conle O.V. 2008. Revision of Oriental Phasmatodea: The tribe Pharnaciini Günther, 1953, including the description of the world's longest insect, and a survey of the family Phasmatidae Gray, 1835 with keys to the subfamilies and tribes (Phasmatodea: “Anareolatae": Phasmatidae). Zootaxa 1906: 1-316.

Whiting M.F., Bradler S. \& Maxwell T. 2003. Loss and recovery of wings in stick insects. Nature 421: 264-267. http://dx.doi.org/10.1038/nature01313

Manuscript received: 26 January 2015

Manuscript accepted: 25 February 2015

Published on: 10 March 2015

Topic editor: Koen Martens

Desk editor: Charlotte Thionois

Printed versions of all papers are also deposited in the libraries of the institutes that are members of the EJT consortium: Muséum national d'Histoire naturelle, Paris, France; Botanic Garden Meise, Belgium; Royal Museum for Central Africa, Tervuren, Belgium; Natural History Museum, London, United Kingdom; Royal Belgian Institute of Natural Sciences, Brussels, Belgium; Natural History Museum of Denmark, Copenhagen, Denmark. 